\title{
Efeitos da população de plantas e de tratamento fitossanitário no rendimento de grãos do feijoeiro comum, cultivar "TPS Nobre"
}

\author{
Effects of plant population and disease control in the crop yield of the common bean, cultivar 'TPS Nobre'
}

\author{
Adilson Jauer ${ }^{1}$ Luiz Marcelo Costa Dutra ${ }^{2}$ Lucio Zabot ${ }^{1}$ Daniel Uhry ${ }^{3}$ Marcos Paulo Ludwig ${ }^{3}$ \\ Juliano Ricardo Farias ${ }^{3}$ Danton Camacho Garcia ${ }^{4}$ Alessandro Dal Col Lúcio ${ }^{4}$ \\ Orlando Antônio Lucca Filho ${ }^{5}$ Miguel Dalmo de Menezes Porto ${ }^{6}$
}

\section{RESUMO}

Foram conduzidos três experimentos, em Santa Maria e em Constantina - RS, com o objetivo de determinar a população mais adequada de plantas para o tipo II de feijoeiro comum, nas condições de cultivo da safra e da safrinha em diferentes regiões climáticas, em função da ocorrência de moléstias. $O$ delineamento experimental adotado foi o de blocos ao acaso, com cinco repetições, no esquema de parcelas divididas. Maior população de plantas apresenta rendimentos superiores ou equivalentes aos obtidos na menor população de plantas, e a ocorrência de moléstias não acarretou redução do rendimento de grãos nas populações maiores.

Palavras-chave: Phaseolus vulgaris, moléstias, tipo II.

\section{ABSTRACT}

Three experiments were conducted in Santa Maria and Constantina - Rio Grande do Sul State - Brazil, to determine the effect of plant population on disease occurrence in common bean (type II grown) in the first and second growing season and to determine the most appropriate plant population. The experiment was established as a split-plot randomized block design with five replications. The results showed that there was no effect of plant population in disease incidence. The high plant populations provided higher or similar grain yield compared with the grain yield of the low plant populations.

Key words: Phaseolus vulgaris, diseases, type II.

\section{INTRODUÇÃO}

O feijoeiro comum é considerado uma cultura de grande importância econômica e social no Brasil, pois representa fonte significativa de proteína vegetal na alimentação do povo brasileiro (RODRIGUES et al., 1999).

A produtividade média do feijoeiro comum no Brasil é considerada baixa devido a várias causas, entre elas, segundo ARF et al., (1997), estão a extrema sensibilidade da cultura às variações climáticas, o uso de sementes com origem e qualidade desconhecidas, a implantação da cultura em solos com acidez elevada, a predominância de cultivos associados com outras culturas, a população de plantas inadequada, a alta sensibilidade a pragas e doenças e a aplicação de quantidade insuficiente de fertilizantes.

Outro aspecto salientado por vários autores (ALCÂNTARA et al.,1991; DUARTE \& ZIMMERMANN, 1994) é que, apesar de o melhoramento ter lançado cultivares com progressos genéticos significativos, este aumento potencial de produtividade dos genótipos não tem sido acompanhado pelo desenvolvimento de práticas culturais que permitam a expressão de seu potencial.

\footnotetext{
${ }^{1}$ Programa de Pós-graduação em Agronomia (PPGA), Centro de Ciências Rurais (CCR), Universidade Federal de Santa Maria (UFSM), 97105-900, Santa Maria, RS, Brasil.

2Departamento de Fitotecnia, CCR, UFSM, 97105-900, Santa Maria, RS, Brasil. Tutor do PET-Agronomia. Email:marcelo@ccr.ufsm.br. Autor para correspondência.

${ }^{3}$ Curso de Agronomia, CCR, UFSM, Santa Maria, RS, Brasil.

${ }^{4}$ Departamento de Fitotecnia, CCR, UFSM, Santa Maria, RS, Brasil.

${ }^{5}$ Departamento de Fitotecnia, Faculdade de Agronomia Eliseu Maciel, Universidade Federal de Pelotas (UFPel), Pelotas, RS, Brasil. ${ }^{6}$ Departamento de Fitossanidade, Faculdade de Agronomia, Universidade Federal do Rio Grande do Sul (UFRGS), Porto Alegre, RS, Brasil.
} 
Em estudos realizados com três cultivares, "Iraí” (hábito determinado arbustivo), "BR 6- Barriga Verde" e "Carioca” (indeterminado prostrado), nas densidades de 100, 200 e 300 mil plantas ha $^{-1}$, semeadas em outubro e dezembro, foi observado aumento do rendimento de grãos, com aumento da população (ALMEIDA \& SANGOI, 1994). Entretanto, LEMOS et al. (1993), com populações de até 300 mil plantas ha ${ }^{-1} \mathrm{e}$ cultivares do tipo II, não observaram diferenças significativas no rendimento.

Na safrinha, JAUER (2002), testando as cultivares "Iraí” do tipo I, "BR IPAGRO 44 Guapo Brilhante" do tipo II e "Pérola" tipo III, nas quatro densidades de semeadura: 200, 300, 400 e 500 mil plantas ha $^{-1}$, constatou que a cultivar "Iraí" não apresentou diferença significativa para o rendimento de grãos, enquanto que, para a cultivar "BR IPAGRO 44 Guapo Brilhante”, o maior rendimento foi obtido na densidade de 340 mil plantas ha ${ }^{-1}$. Este comportamento difere das atuais recomendações para plantas do tipo I e II para o Estado do Rio Grande do Sul. Entretanto, para a cultivar "Pérola", o maior rendimento foi observado na densidade de 200 mil plantas ha $^{-1}$, mesma densidade das atuais recomendações.

Entre os fatores responsáveis pelo baixo rendimento da cultura também encontram-se as moléstias, as quais podem ser de origem fúngica, bacteriana, virótica e as incitadas por nematóides (SARTORATO \& RAVA, 2003).

Em virtude do uso de uma maior população de plantas, seja pela diminuição do espaçamento entre linhas e/ou pelo aumento do número de plantas na linha de semeadura, haveria tendência a um aumento na ocorrência de moléstias pela formação de um microclima favorável ao desenvolvimento de fitopatógenos, especialmente fungos de (FERRAZ \& CAFÉ FILHO, 1995). Esses autores observaram o efeito da arquitetura do dossel e da população de plantas sobre a antracnose (Colletotrichum lindemunthianum) e constataram que plantas de hábito semiprostrado apresentaram maior incidência e severidade da moléstia que plantas de hábito ereto, aumentando linearmente com o aumento da densidade de 200 para 400 mil plantas ha ${ }^{-1}$. No entanto, SCHUCH et al. (1993), em trabalho relacionando populações (100, 200, 350 e 500 mil plantas ha $\left.{ }^{-1}\right)$ e espaçamentos (25, 50 e $75 \mathrm{~cm}$ entre linhas) para a cultivar "Rio Tibagi”, não observaram efeito destes fatores sobre a antracnose e o crestamento bacteriano comun.

O objetivo do presente trabalho foi determinar a população mais adequada de plantas para as cultivares dos tipos II de feijoeiro comum nas condições de cultivo da safra e da safrinha em diferentes regiões climáticas, em função da ocorrência de moléstias.

\section{MATERIAL E MÉTODOS}

Foram conduzidos três experimentos em Santa Maria-RS e três em Constantina-RS, avaliandose a variedade cultivada "TPS Nobre” em três épocas de semeadura. Em Santa Maria, na Depressão Central, a uma altitude de $95 \mathrm{~m}$, latitude $29^{\circ} 42^{\prime} 24^{\prime \prime}$ S e longitude $53^{\circ} 48$ ’ 42 ” W, experimentos foram conduzidos na área do Departamento de Fitotecnia no Campus da Universidade Federal de Santa Maria. O solo é classificado no Sistema Brasileiro de Classificação de Solos (EMBRAPA, 1999) como ARGISSOLO VERMELHO distrófico arênico. Em Constantina, na Região do Planalto, altitude de $501 \mathrm{~m}$, latitude $27^{\circ} 30^{\prime}$ $10^{\prime \prime}$ e $27^{\circ} 48^{\prime} 29^{\prime \prime}$ S e longitude $52^{\circ} 54^{\prime} 28^{\prime \prime}$ e $53^{\circ} 07^{\prime} 20^{\prime \prime}$ $\mathrm{W}$, experimentos foram conduzido na área de um produtor rural, em solo classificado no Sistema Brasileiro de Classificação de Solos (EMBRAPA, 1999) como LATOSSOLO VERMELHOAluminoférrico típico.

A adubação das áreas foi realizada de acordo com os resultados da análise de solo, em concordância com as recomendações da ROLAS (1994) para a cultura do feijoeiro. Antes da instalação dos experimentos, as sementes foram tratadas com captan e carboxin + thiram. A adubação em cobertura foi realizada a lanço, aos 18 dias após a emergência, com $80 \mathrm{~kg} \mathrm{ha}^{-1}$ de uréia.

Utilizou-se a cultivar "TPS Nobre” (tipo II), em três épocas (na safra 2002, na safrinha e na safra de 2003). Em cada experimento, foram avaliados duas populações de plantas: 250 e 350 mil plantas ha-1 (a primeira recomendada pela Comissão Estadual de Pesquisa de Feijão, CEPEF, 2000, e a segunda sugerida pelos autores) e dois níveis de controle de moléstia: sem e com uma aplicação do indutor de resistência acibenzolar-s-methyl e duas aplicações de tiofanato metílico, uma em R6 (floração: abertura da primeira flor) e outra 15 dias após, em R8 (enchimento dos legumes).

O delineamento experimental utilizado foi o de blocos ao acaso, com cinco repetições, em parcelas divididas, sendo o local a parcela principal, população de plantas a subparcela e controle de moléstias a subsubparcela. A subsubparcela constituiu-se de cinco linhas com 6,0m de comprimento, espaçadas 0,40m. A área útil foi constituída das três linhas centrais descontando 1,0m nas extremidades como bordadura. A semeadura foi realizada com o auxílio de semeadora com excesso de sementes e, posteriormente, foram desbastadas nas populações desejadas.

Para análise do rendimento, as plantas da área útil foram arrancadas e, posteriormente, trilhadas 
em trilhadora estacionária, os grãos limpos foram pesados e foi feita a determinação do teor de umidade, sendo, em seguida, calculado o rendimento, em kg ha-1, com correção da massa para a umidade de $13 \%$.

A análise estatística para os experimentos individuais foi realizada por meio da análise da variância individual para cada experimento. Em seguida, foram testadas as grandezas dos quadrados médios do erro (QMe), pelo teste do "F” máximo, e considerados homogêneos (quando a relação entre o maior e o menor QMe não foi superior a mais de quatro vezes) todos os anos incluídos na análise conjunta sem restrições (FERREIRA, 1991).

Posteriormente, as análises foram interpretadas e, quando significativos os efeitos principais e/ou interações, foram analisados individualmente pelo teste Tukey a 5\% de probabilidade de erro. Os experimentos foram analisados com auxílio do programa estatístico SOC - NTIA (EMBRAPA, 1997).

\section{RESULTADOS E DISCUSSÃO}

Os resultados da análise conjunta para o rendimento de grãos são apresentados na tabela 1 . O comportamento demostra que a variável estudada apresentou alguma diferença significativa entre os anos, podendo esta ser para o fator simples e/ou para as interações dupla e/ou tripla, ou seja, o comportamento para a variável não se manteve constante para as épocas e, os anos de realização dos experimentos,

Tabela 1 - Resumo da análise da variância conjunta. O fator A são os cultivos (safra 2002, safrinha e safra de 2003); o fator C, a união dos locais (Santa Maria e Constantina) com populações de plantas (250 e 350 mil plantas ha ${ }^{-1}$ ) e o fator D é com e sem tratamento fitossanitário para a variável rendimento de grãos da cultivar "TPS Nobre”.

\begin{tabular}{llc}
\hline & & Quadrado médio \\
\cline { 3 - 3 } Fonte de variação & GL & Rendimento de grãos \\
\hline Bloco (AD) & 24 & 68305,7375 \\
Anos ( A) & 2 & $2565982,11^{*}$ \\
Tratamento (D) & 1 & $2887651,88^{*}$ \\
A X D & 2 & $42249,025^{\text {ns }}$ \\
Combinação (C) & 3 & $1166331,52^{*}$ \\
A x C & 6 & $1235348,13^{*}$ \\
C x D & 3 & $121719,408^{\text {ns }}$ \\
A x C x D & 6 & $263299,825^{*}$ \\
ERRO MÉDIO & 72 & 64204,29305 \\
\hline
\end{tabular}

${ }^{(\mathrm{ns})}=$ não significativo, ${ }^{(*)}=$ significativo a $5 \%$ de probabilidade de erro. necessitando-se, com isso, realizar-se a discussão e as interpretações individuais para cada experimento.

No Rio Grande do Sul, com cultivar do tipo II, WESTPHALEN et al. (1977), HOFFMANN JUNIOR et al. (2001) observaram diferença entre as épocas de semeadura. Em outros estados, quando comparadas as épocas de cultivos, outros pesquisadores também encontraram diferença para cultivares do tipo II, como ALMEIDA \& SANGOI (1994) em Santa Catarina, CARVALHO et al. (1998) em São Paulo, BRANDES et al. (1972) em Minas Gerais.

Para o rendimento de grãos (Tabela 2), na safra de 2002, foram detectadas interações envolvendo todos os fatores analisados. A interação população de plantas versus locais (Tabela 3) demonstrou que, em Santa Maria-RS, com 250 mil planta ha-1 ${ }^{-1}$ o rendimento de grãos foi menor o que com 350 mil plantas ha-1 . O mesmo comportamento também foi observado por JAUER et al. (2003) trabalhando com populações de 200, 300, 400 e 500 mil plantas ha ${ }^{-1}$, os quais observaram, para cultivar do tipo II, maior rendimento com $340 \mathrm{mil}$ plantas ha-1. Por outro lado, LEMOS et al. (1993) e ALMEIDA \& SANGOI (1994), com populações de até 300 mil plantas ha ${ }^{-1}$ para cultivares do tipo II, não observaram diferenças no rendimento de grãos.

A interação entre locais versus tratamento fitossanitário (Tabela 3) demonstrou que, em Santa Maria, não houve ocorrência de moléstias que implicasse a redução do rendimento de grãos. No entanto, em Constantina, a ausência de tratamento fitossanitário redundou em rendimento menor do que o das parcelas tratadas. Isso demonstra que a ocorrência de moléstias em Constantina contribuiu significativamente para reduzir o nível de produtividade.

Em trabalho realizado por BONINI et al. (2001), também foram observadas diferenças de produtividade entre locais devido à ocorrência de moléstias. ITO et al. (1999), RODRIGUES et al. (1999) e RAVA (2002), testando produtos fitossanitários, constataram que todos apresentaram rendimento superior ao da testemunha (sem aplicação de fungicida).

O rendimento de grãos (Tabela 3), na safra de 2003, apresentou diferenças entre os locais, sendo o maior valor observado em Constantina, com $2.050 \mathrm{~kg}$ ha $^{-1}$. SANDER et al. (2001), no Rio Grande do Sul, com cultivar do tipo II, também observaram diferença entre locais para o rendimento de grãos.

O fator população de plantas (Tabela 3) não apresentou diferenças para o rendimento de grãos. BRANDES et al. (1972), testando densidades de 125 mil a um milhão de plantas por hectare, com a cultivar “Rico 23” (hábito de crescimento indeterminado tipo 
Efeitos da população de plantas e de tratamento fitossanitário no rendimento de grãos de feijoeiro comum...

Tabela 2 - Rendimento de grãos da cultivar “TPS Nobre” em Santa Maria (SM) e em Constantina (CST), em função de duas populações de plantas e do tratamento fitossanitário, cultivada na safra 2002, na safra e na safrinha de 2003 - RS.

\begin{tabular}{|c|c|c|c|c|c|}
\hline & & \multicolumn{2}{|c|}{ População de plantas } & \multicolumn{2}{|c|}{ Tratamento fitossanitário } \\
\hline \multicolumn{2}{|c|}{ Local } & \multicolumn{4}{|c|}{ Safra de 2002} \\
\hline SM & ${ }^{\mathrm{C}} 2062 \mathrm{a}^{*}$ & 250 mil & ${ }^{\mathrm{C}} 1931 \mathrm{~b}$ & $\mathrm{COM}$ & ${ }^{\mathrm{C}} 2191 \mathrm{a}$ \\
\hline CST & 1944a & 350 mil & $2074 \mathrm{a}$ & SEM & $1815 \mathrm{~b}$ \\
\hline CV (\%) & 14,21 & CV (\%) & 5,63 & CV (\%) & 17,09 \\
\hline \multirow{2}{*}{\multicolumn{2}{|c|}{ Local }} & \multirow{2}{*}{\multicolumn{2}{|c|}{ População de plantas }} & \multirow{2}{*}{\multicolumn{2}{|c|}{ Tratamento fitossanitário }} \\
\hline & & & & & \\
\hline SM & $1069 \mathrm{~b}$ & $250 \mathrm{mil}$ & $1590 \mathrm{a}$ & $\mathrm{COM}$ & $1714 \mathrm{a}$ \\
\hline CST & 2050 a & $350 \mathrm{mil}$ & 1529 a & SEM & $1406 \mathrm{~b}$ \\
\hline CV (\%) & 11,91 & CV (\%) & 18,88 & CV (\%) & 14,44 \\
\hline \multirow{2}{*}{\multicolumn{2}{|c|}{ Local }} & \multirow{2}{*}{\multicolumn{2}{|c|}{ População de plantas }} & \multirow{2}{*}{\multicolumn{2}{|c|}{ Tratamento fitossanitário }} \\
\hline & & & & & \\
\hline SM & $1534 \mathrm{a}$ & 250 mil & 1505 a & $\mathrm{COM}$ & $1692 \mathrm{a}$ \\
\hline CST & 1603 a & $350 \mathrm{mil}$ & 1632 a & SEM & $1445 \mathrm{~b}$ \\
\hline CV (\%) & 18,02 & CV (\%) & 13,31 & CV (\%) & 15,46 \\
\hline
\end{tabular}

*= Médias não seguidas de mesma letra na coluna diferem entre si pelo teste $\mathrm{F}$ em nível $\alpha=5 \%$ de probabilidade de erro. ${ }^{\mathrm{C}}=$ Interação significativa.

II), em Minas Gerais, verificaram que, no período das "águas”, as populações utilizadas praticamente não afetaram a produtividade da cultura. O mesmo comportamento também foi observado por SCHUCH et al. (1993) e por LEMOS et al. (1993).

O rendimento de grãos (Tabela 3) apresentou diferenças quando comparado com e sem tratamento fitossanitário (Tabela 3), sendo observado maior rendimento $\left(1.714 \mathrm{~kg} \mathrm{ha}^{-1}\right)$ quando realizado o controle de moléstias. Resultados similares quanto ao comportamento do rendimento de grãos também foram observados por ITO et al. (1999), RODRIGUES et al. (1999), BONINI et al. (2001) e RAVA (2002) que, testando produtos fitossanitários, constataram que todos apresentaram rendimento superior ao da testemunha (sem aplicação de fungicida).

Na safrinha de 2003, o rendimento de grãos (Tabela 3) da cultivar "TPS Nobre" não apresentou diferenças entre os locais estudados, com média de $1.568 \mathrm{~kg} \mathrm{ha}^{-1}$. O fator população de plantas para a

Tabela 3 - Desdobramento das interações entre local (Santa Maria e Constantina) versus população ( 250 e 350 mil plantas ha ${ }^{-1}$ ) e local versus tratamento fitossanitário (com e sem tratamento) para a variável rendimento de grãos ( $\left.\mathrm{kg} \mathrm{ha}^{-1}\right)$ da cultivar "TPS Nobre" cultivada na safra $2002-\mathrm{RS}$

\begin{tabular}{|c|c|c|c|}
\hline \multirow{2}{*}{ População de plantas $\left(\mathrm{n}^{\circ}{ }^{\circ} \mathrm{ha}^{-1}\right)$} & Santa Maria & Constantina & Média \\
\hline & \multicolumn{3}{|c|}{ Rendimento de grãos $\left(\mathrm{kg} \mathrm{ha}^{-1}\right)$} \\
\hline $250 \mathrm{mil}$ & $1875 \mathrm{Ba}^{*}$ & 1988 Аа & 1931 \\
\hline 350 mil & 2249 Аа & 1898 Аа & 2074 \\
\hline Média & 2062 & 1944 & \\
\hline \multirow{2}{*}{ Tratamento fitossanitário } & Santa Maria & Constantina & Média \\
\hline & \multicolumn{3}{|c|}{ Rendimento de grãos $\left(\mathrm{kg} \mathrm{ha}^{-1}\right)$} \\
\hline Com tratamento & 2063 Аа & 2319 Аа & 2191 \\
\hline Sem tratamento & $2061 \mathrm{Aa}$ & $1568 \mathrm{Bb}$ & 1815 \\
\hline Média & 2062 & 1944 & \\
\hline
\end{tabular}

*= Médias seguidas de mesma letra maiúscula na coluna e de minúscula na linha não diferem entre si pelo teste Tukey em nível $\alpha=5 \%$ de probabilidade.

Ciência Rural, v.36, n.5, set-out, 2006. 
variável rendimento de grãos (Tabela 3) não apresentou diferenças, sendo o seu valor médio de $1.568 \mathrm{~kg} \mathrm{ha}^{-1}$. THOMAZ (2001), na safrinha, avaliando três cultivares de hábito de crescimento indeterminado (uma do tipo II, duas do tipo III), em cinco populações de plantas

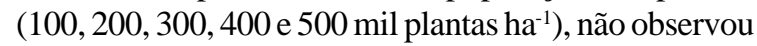
diferenças para o rendimento de grãos. Este comportamento se deve, segundo o autor, provavelmente o fato de que as, plantas de crescimento indeterminado, quando nutridas adequadamente, mesmo em menores populações, mantêm a produção por área idêntica à das maiores populações, porque nas menores populações a produção individual das plantas aumenta suficientemente para obter rendimentos satisfatórios. Entretanto, JAUER et al. (2003), na safrinha, testando a cultivar "BR IPAGRO 44 Guapo Brilhante" (tipo II) em quatro densidades de semeadura (200, 300, 400 e 500 mil plantas ha-1), constatou o maior rendimento na densidade de 340 mil plantas ha-1.

O rendimento de grãos apresentou diferenças para o fator tratamento fitossanitário (Tabela 3), sendo o maior valor observado quando realizado o controle de moléstias, com $1.692 \mathrm{~kg} \mathrm{ha}^{-1}$.

Acreditava-se válido esperar que o aumento na população de plantas por área promovesse um fechamento mais rápido do dossel e um maior índice de área foliar propiciasse um microclima mais favorável à ocorrência e à proliferação das moléstias. Entretanto, isto não foi evidenciado neste trabalho, pois a interação população de plantas e tratamento fitossanitário não foi significativa. THOMAZ (2001); JAUER (2002), trabalhando com cultivar do tipo II em diferentes populações de plantas, na safrinha, observaram aumento do índice de área foliar com o aumento da população de plantas.

\section{CONCLUSÕES}

A maior população de plantas apresenta rendimentos superiores ou equivalentes aos obtidos na menor população de plantas. A ocorrência de moléstias não acarreta redução do rendimento de grãos das populações maiores. Maiores populações de plantas não acarretam aumento na incidência de doenças.

\section{REFERÊNCIAS}

ALCÂNTRA, J.P. et al. Avaliação de cultivares de feijoeiro (Phaseolus vulgaris L.) em diferentes densidades de semeadura e condições de ambiente. Ciência e Prática, Lavras, v.15, p.331-428, 1991.

ALMEIDA, M.L.; SANGOI, L. Manejo de cultivares de feijão de diferentes hábitos de crescimento no planalto catarinense.
Rendimento de grãos. Ciência Rural, Santa Maria, v. 24, n.3, p.513-517, 1994.

ARF, O. et al. Efeito de diferentes espaçamentos e densidades em feijoeiro (Phaseolus vulgaris L.) adubado de acordo com a área e a população de plantas. Científica, São Paulo, v.25, n.1, p.45-57, 1997.

BONINI, J.V. et al. Controle químico de doenças na cultura do feijoeiro em cultivo de safra. In: COMISSÃO ESTADUAL DE PESQUISA DE FEIJÃO; Reunião da Comissão Estadual de Pesquisa de Feijão, 2001, Erechim, RS. Anais... Erechim/RS: São Cristóvão, 2001. 208p. p.133-137.

BRANDES, D. et al. Efeito da população de plantas e da época de plantio no crescimento do feijoeiro (Phaseolus vulgaris L.), mudanças morfológicas e produção de matéria seca. Experientiae, Viçosa, v.14, n.1, p.1-48, 1972.

CARVALHO, M.A.C. et al. Efeito do espaçamento e época de semeadura sobre o desempenho do feijão. I. Qualidade fisiológica das sementes. Revista Brasileira de Sementes, v.20, n.1, p.202-208, 1998.

Comissão Estadual de Pesquisa de Feijão. Recomendações técnicas para o cultivo no Rio Grande do Sul. Santa Maria: Comissão Estadual de Pesquisa de Feijão, 2000. 80p.

DUARTE, J.B.; ZIMMERMANN, M.J.O. Adaptabilidade e estabilidade de rendimento de genótipos de feijoeiro comum. Pesquisa Agropecuária Brasileira, Brasília, v.29, n.1, p.2532, 1994.

EMBRAPA. Ambiente de software NTIA, versão 4.2.2: manual do usuário - ferramental estatístico. Campinas: Centro Nacional de Pesquisa Tecnológica em Informática para a Agricultura, 1997. 258p.

EMBRAPA. Centro Nacional de Pesquisa de Solos (Rio de Janeiro, RJ). Sistema Brasileiro de Classificação de Solos - Brasília: EMBRAPA Produção de Informações; RJ: EMBRAPA Solos, 1999. XXVI, 412p.

FERRAZ, L.C.L.; CAFÉ FILHO, A.C.C. Efeito de arquitetura do dossel da planta e densidade de plantio na incidência e severidade de antracnose do feijoeiro. Fitopatologia Brasileira, v.20, p.124-130, 1995.

FERREIRA, P.V. Estatística experimental aplicada à agronomia. Maceió: EDUFQAL, 1991. 437p.

HOFFMAN JUNIOR, L. et al. Avaliação de genótipos de feijão preto e de cor em duas épocas de semeadura. In: COMISSÃO ESTADUAL DE PESQUISA DE FEIJÃO, 2001, ERECHIM, RS. Anais... Erechim, RS: São Cristóvão, 2001. 208p. p.75-80.

ITO, M.F. et al. Eficiência de tebuconazole, associado a outros fungicidas, no controle da antracnose e mancha angular do feijoeiro. In: REUNIÃO NACIONAL DE PESQUISA DE FEIJÃO, 6., 1999, Salvador, BA. Anais... Santo Antônio de Goiás: Embrapa Arroz e feijão, 1999. 880p. p.185-187.

JAUER, A. População de plantas na cultura do feijoeiro comum (Phaseolus vulgaris L.) cultivado na safrinha. 2002. 164f. Dissertação (Mestrado em Agronomia) - Curso de Pósgraduação em Agronomia, Universidade Federal de Santa Maria. 
JAUER, A. et al. Comportamento da cultivar BR-IPAGRO 44Guapo Brilhante de feijoeiro em quatro populações de plantas na safrinha em, Santa Maria-RS. Ciência Rural, Santa Maria, v.33, n.2, p.201-206, 2003.

LEMOS, L.B. et al. Comportamento de cultivares de feijoeiro com distintos hábitos de crescimento, em diferentes populações, em semeadura de inverno. Científica, São Paulo, v.21, n.1, p.113-120, 1993.

RAVA, C.A. Eficiência de fungicidas no controle da antracnose e da mancha angular do feijoeiro comum. Summa Phytopathologica. v.28, n.1, p.65-69, 2002.

RODRIGUES, F.A. et al. Influência de semeaduras sucessivas de feijoeiro na severidade da mancha angular e ferrugem e perdas na produção. Pesquisa Agropecuária Brasileira, Brasília, v.34, n.8, p.1373-1378, 1999

ROLAS. Recomendações de adubação e de calagem para os estados do Rio Grande do Sul e de Santa Catarina. 3.ed. Passo Fundo: SBCS-Núcleo Regional Sul, 1994. 224p.

SANDER, G.R. et al. Ensaio de valor de cultivo e uso de genótipos de feijão conduzidos pela FEPAGRO em 2000/2001 no período da safra. In: COMISSÃO ESTADUAL DE PESQUISA DE FEIJÃO, 2001, Erechim, RS. Anais... Erechim, RS: São Cristóvão, 2001. 208p. p.85-87.

SARTORATO, A.; RAVA, C.A. Controle químico da mancha angular do feijoeiro comum. Summa Phytopathologica, v.29, n.2, p.202-204, 2003.

SCHUCH, L.Q.B. et al. Resposta do feijoeiro a variação no espaçamento e população de plantas. In: REUNIÃO NACIONAL DE PESQUISA DE FEIJÃO, 4., 1993, Londrina, PR. Anais... Londrina, PR: IAPAR, 1993. 200p. p.67.

THOMAZ. L.F. População de plantas para feijoeiro comum (Phaseolus vulgaris L.) na safrinha em Santa Maria-RS. 2001. 129f. Dissertação (Mestrado em Agronomia) - Curso de Pós-graduação em Agronomia, Universidade Federal de Santa Maria.

WESTPHALEN, S.L. et al. Determinação das influencias de elementos meteorológicos no rendimento de cultivares de feijão em diferentes épocas de semeadura. In: REUNIÃO TÉCNICA ANUAL DO FEIJÃO, 1977, Porto Alegre, RS. Ata... Porto Alegre: IPAGRO, 1977. p.35-49. 